\title{
Prospective risk of stillbirth and neonatal complications in twin pregnancies: systematic review and meta-analysis
}

\author{
Fiona Cheong-See, 1 Ewoud Schuit,, 2,3,4 David Arroyo-Manzano, ${ }^{5}$ Asma Khalil, 6 Jon Barrett,7 K S Joseph,8 \\ Elizabeth Asztalos, ${ }^{9}$ Karien Hack, ${ }^{10}$ Liesbeth Lewi, ${ }^{11}, 12$ Arianne Lim, ${ }^{13}$ Sophie Liem, ${ }^{13}$ Jane E Norman, ${ }^{14}$ \\ John Morrison, ${ }^{15}$ C Andrew Combs, ${ }^{16}$ Thomas J Garite, ${ }^{16,17}$ Kimberly Maurel, ${ }^{16}$ Vicente Serra, ${ }^{18,19}$ \\ Alfredo Perales, ${ }^{19,20}$ Line Rode, ${ }^{21}$ Katharina Worda, ${ }^{22}$ Anwar Nassar,, ${ }^{23}$ Mona Aboulghar, ${ }^{24}$ Dwight Rouse, ${ }^{25}$ \\ Elizabeth Thom, ${ }^{26}$ Fionnuala Breathnach, ${ }^{26}$ Soichiro Nakayama, ${ }^{27}$ Francesca Maria Russo, ${ }^{28}$ \\ Julian N Robinson, ${ }^{29}$ Jodie M Dodd, ${ }^{30}$ Roger B Newman, ${ }^{31}$ Sohinee Bhattacharya,, 32 Selphee Tang, ${ }^{33}$ \\ Ben Willem J Mol, ${ }^{34}$ Javier Zamora, ${ }^{35,36}$ Basky Thilaganathan, ${ }^{6}$ Shakila Thangaratinam ${ }^{1}$ A Global \\ Obstetrics Network (GONet) Collaboration
}

\begin{abstract}
For numbered affiliations see end of article.

Correspondence to: J Zamora javier.zamora@hrc.es

Additional material is published online only. To view please visit the journal online.

Cite this as: BMJ 2016;354:i4353 http://dx.doi.org/10.1136/bmj.i4353 Accepted: 6 August 2016
\end{abstract}

\section{ABSTRACT}

OBJECTIVE

To determine the risks of stillbirth and neonatal complications by gestational age in uncomplicated monochorionic and dichorionic twin pregnancies.

\section{DESIGN}

Systematic review and meta-analysis.

DATA SOURCES

Medline, Embase, and Cochrane databases (until December 2015).

REVIEW METHODS

Databases were searched without language restrictions for studies of women with uncomplicated twin pregnancies that reported rates of stillbirth and neonatal outcomes at various gestational ages. Pregnancies with unclear chorionicity, monoamnionicity, and twin to twin transfusion syndrome were excluded. Meta-analyses of observational studies and cohorts nested within randomised studies were undertaken. Prospective risk of stillbirth was computed for each study at a given week of gestation and compared with the risk of neonatal death among deliveries in the same week. Gestational age specific differences in risk were estimated for stillbirths and neonatal deaths in monochorionic and dichorionic twin pregnancies after 34 weeks' gestation.

RESULTS

32 studies (29685 dichorionic, 5486 monochorionic pregnancies) were included. In dichorionic twin pregnancies beyond 34 weeks (15 studies, 17830

\section{WHAT IS ALREADY KNOWN ON THIS TOPIC}

The risk of stillbirth is higher in twin pregnancies than in singleton pregnancies Risk increases with advancing gestational age in uncomplicated monochorionic and dichorionic twin pregnancies

\section{WHAT THIS STUDY ADDS}

For women with dichorionic twin pregnancies, delivery should be considered at 37 weeks' gestation to prevent the significant increase in stillbirths associated with expectant management compared with the risk of neonatal deaths associated with early delivery

In monochorionic twin pregnancies, there is no clear evidence to support routine delivery before 36 weeks' gestation

pregnancies), the prospective weekly risk of stillbirths from expectant management and the risk of neonatal death from delivery were balanced at 37 weeks' gestation (risk difference 1.2/1000, 95\% confidence interval -1.3 to $3.6 ; I^{2}=0 \%$ ). Delay in delivery by a week (to 38 weeks) led to an additional 8.8 perinatal deaths per 1000 pregnancies ( $95 \%$ confidence interval 3.6 to $\left.14.0 / 1000 ; I^{2}=0 \%\right)$ compared with the previous week. In monochorionic pregnancies beyond 34 weeks (13 studies, 2149 pregnancies), there was a trend towards an increase in stillbirths compared with neonatal deaths after 36 weeks, with an additional 2.5 per 1000 perinatal deaths, which was not significant $(-12.4$ to $\left.17.4 / 1000 ; I^{2}=0 \%\right)$. The rates of neonatal morbidity showed a consistent reduction with increasing gestational age in monochorionic and dichorionic pregnancies, and admission to the neonatal intensive care unit was the commonest neonatal complication. The actual risk of stillbirth near term might be higher than reported estimates because of the policy of planned delivery in twin pregnancies.

\section{CONCLUSIONS}

To minimise perinatal deaths, in uncomplicated dichorionic twin pregnancies delivery should be considered at 37 weeks' gestation; in monochorionic pregnancies delivery should be considered at 36 weeks.

SYSTEMATIC REVIEW REGISTRATION PROSPERO CRD42014007538.

\section{Introduction}

Twin pregnancies are high risk, with a thirteenfold increase in rates of stillbirth in monochorionic and a fivefold increase in dichorionic twins compared with singleton pregnancies. ${ }^{1-3}$ Uncomplicated twin pregnancies are often delivered early in an attempt to prevent late stillbirth. Delivery before term is associated with neonatal complications associated with prematurity. ${ }^{1}$ Since 2005, the number of patient safety incidents involving multiple pregnancies, including unexpected stillbirth and neonatal death, has risen by $419 \%$ in UK, and peaked in 2013-14, resulting in payouts of over $€ 90 \mathrm{~m}(\$ 117 \mathrm{~m}, € 105 \mathrm{~m}) .45$ The recent global drive to prevent stillbirth has highlighted multiple pregnancy as a major risk factor in high income countries, ${ }^{6}$ with calls to prioritise evaluation of timing of delivery and outcomes in twin pregnancies. ${ }^{7}$ 
The optimal gestational age for delivery that minimises fetal and neonatal complications in twin pregnancies is not known. Current recommendations vary on the timing of delivery, starting from 34 up to 37 weeks' gestation in monochorionic twin pregnancies ${ }^{8}$ and from 37 up to 39 weeks in dichorionic twin pregnancies. ${ }^{9-12}$ Women and their partners, clinicians, and guideline makers need robust estimates of the risk of stillbirth from continuing the pregnancy and the neonatal risk from early delivery to decide on the optimal timing of delivery. Existing reviews have focused mainly on the risk of stillbirth, without taking neonatal outcomes into account. ${ }^{13}$ There are no published data on perinatal mortality and morbidity for specific gestations and chorionicity in twins to guide decision making on the timing of delivery. ${ }^{14}$ Furthermore, randomised trials on timing are not adequately powered to provide robust estimates of benefit. ${ }^{1516}$

We summarised data from individual studies to quantify the prospective risks of stillbirth in women with uncomplicated monochorionic and dichorionic twin pregnancies, as well as the risks to the newborn, when delivered after 34 weeks' gestation and at various gestational ages.

\section{Methods}

We conducted the systematic review based on a prospective protocol ${ }^{17}$ and reported according to the Preferred Reporting Items for Systematic Reviews and Meta-analyses (PRISMA) guidelines). ${ }^{18}$

\section{Identification of studies}

We searched the major electronic databases Medline, Embase, and Cochrane Library using the NHS Evidence website and Cochrane online library platforms from inception until December 2015 for studies on twin pregnancies that reported rates of stillbirth. Search terms representing the participants ('monochorionic' OR 'dichorionic' OR 'twin pregnancy' OR 'multiple pregnancy') were combined with outcome terms ('stillbirth' OR ('fetal or foetal or fetus or foetus' AND 'death or demise or mortality')). We supplemented this search with an additional search for neonatal outcomes in twin pregnancies (appendix 1). We searched the reference lists of included studies. There were no language restrictions. Additionally, we contacted individual authors members of the collaborative research networks such as Global Obstetric Network (GONet), ${ }^{19}$ Evidence Based Medicine Connect (EBM Connect), ${ }^{20}$ and the Twin pregnancies Individual Participant Data (IPD) Meta-Analysis group for relevant data. ${ }^{21}$

\section{Study selection}

Two independent reviewers (FC-S and ES) used a two stage process to select the studies. In the first stage, they assessed abstracts and titles of citations for their eligibility. In the second stage, we obtained the full texts of the studies that seemed to fulfil the inclusion criteria for evaluation.

We included observational cohort studies and cohorts nested in randomised studies on rates of still- birth or neonatal outcomes in monochorionic and/or dichorionic twin pregnancies. Exclusion criteria were unclear chorionicity, monoamnionicity, inability to exclude twin to twin transfusion syndrome in fetuses, and outcomes not provided in weekly or two weekly gestational periods.

We defined stillbirth as a baby born without signs of life after the age of viability or any other definition used by the authors. Neonatal mortality was defined as death up to 28 days after delivery. For infants born after 34 completed weeks of gestation, we considered the following morbidity outcomes to be clinically relevant: need for assisted ventilation, respiratory distress syndrome, septicaemia, hypoxic ischaemic encephalopathy or neonatal seizures, and admission to the neonatal intensive care unit. For preterm infants born between 26 and 33+6 weeks' gestation, in addition to the above, we assessed the rates of bronchopulmonary dysplasia, necrotising enterocolitis, significantly abnormal results on cranial ultrasound scan (cystic periventricular leukomalacia or grade 3 or 4 intraventricular haemorrhage), and retinopathy of prematurity (stages 3 to 5) (appendix 2).

\section{Quality assessment and data extraction}

Two independent reviewers (FCS and ES) evaluated the quality of the studies by investigating separate parameters for the internal validity (the extent to which the information is probably free from bias) and external validity (the representativeness of the population). ${ }^{22-24}$ We evaluated individual parameters such as study design, method of sampling, adequacy of follow-up, ascertainment of the outcome, and appropriate determination of gestational age and chorionicity for internal validity. Studies with features such as prospective design, consecutive or random recruitment of patients, follow-up rates of over $80 \%$, and use of signs on first trimester ultrasonography to determine chorionicity and gestational age were considered to have a low risk of bias. Studies without these features or with unclear reporting were classified to have high risk of bias. We categorised the studies with the following criteria to be highly representative for external validity: clear definition of uncomplicated twin pregnancies, exclusion of pregnancies in which one or both babies were diagnosed antenatally with growth restriction, or major congenital abnormalities. Any discrepancies were resolved after discussion with a third reviewer (ST).

\section{Analysis}

We undertook separate analyses for risks of stillbirth and neonatal complications in monochorionic and dichorionic twin pregnancies in two periods: from 34 weeks' gestation and beyond and early preterm $(<34$ weeks') gestation. From 34 weeks onwards, we estimated the risks by weekly gestational ages, with the 34 week period representing pregnancies entering the $34+0$ to 34+6 weeks' gestation with live fetuses, and so forth. For early preterm ( $<34$ weeks') gestation, we estimated risks of outcomes by two weekly intervals.

We computed the weekly prospective risk of stillbirth by dividing the number of stillbirths observed at that 
week by the number of women at risk in the same week. For a given gestational age, we defined women at risk of stillbirth as those who were still pregnant at the beginning of the week. We corrected for deliveries in that week by subtracting half the number of women who delivered that week. ${ }^{25}$ For risk of neonatal death, we used a similar approach and divided the number of neonatal deaths observed by the number of deliveries that week.

In pregnancies beyond 34 weeks' gestation, we assessed the competing risks of expectant management versus delivery at a particular gestational age for each study. We defined the risk of perinatal death at a given gestational week as the difference between risk of stillbirth and risk of neonatal death for deliveries in that week. This provided a direct measure of benefit or harm from expectant management versus immediate delivery strategy. A difference of less than zero indicates a reduction in the risk of perinatal death with expectant management at that gestational age compared with immediate delivery. We pooled risk differences from individual studies using a fixed effect model weighted by the inverse of its variance. We computed $\mathrm{I}^{2}$ as an estimation of heterogeneity between studies and assumed values lower than $50 \%$ as little heterogeneity and $\mathrm{I}^{2}$ greater than $75 \%$ as substantial heterogeneity.

We estimated the weekly risk of neonatal outcomes by fitting multilevel random effects logistic regression models with gestational age as the unique categorical independent variable. The units of the analysis were pregnancies (first level) that were clustered within studies (second level of the analysis). We obtained point estimates of the risk of each event by the gestational period with its corresponding $95 \%$ confidence interval.

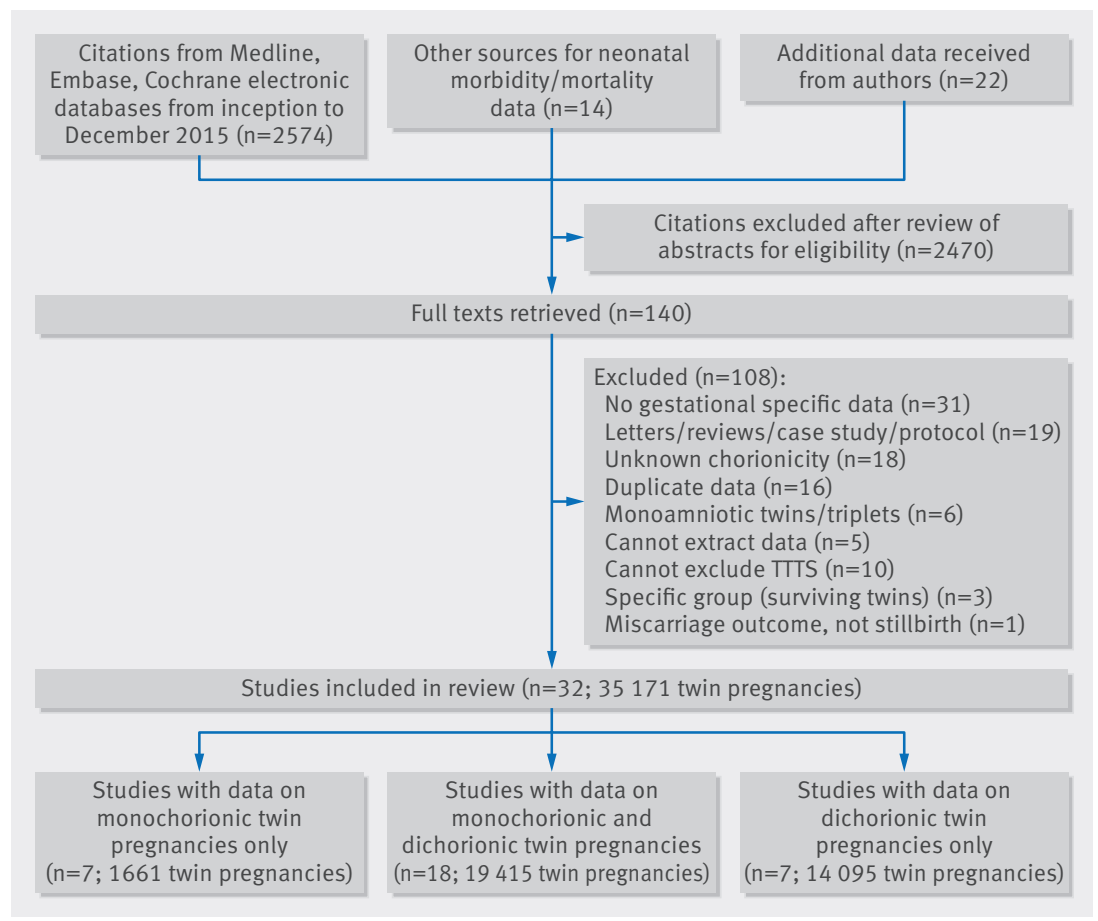

Fig 1 Study selection process in systematic review on prospective risk of stillbirth and neonatal complications in uncomplicated twin pregnancies ( $\Pi T T=$ twin to twin transfusion syndrome)
Before analysis we planned to restrict our evaluation up to the gestational week for which robust unbiased data were available.

Sensitivity analysis was planned before analysis to exclude studies involving pregnancies complicated by congenital abnormalities and those with low external validity. We assessed publication bias and small study effect using funnel plots representing overall event rate (logit scale) versus the inverse of sample size for each study included in main analysis. ${ }^{26}$ Peter's test was used to evaluate funnel asymmetry by fitting a weighted linear regression with the logit of event rate as dependent variable and the inverse of sample size as independent variable. We computed weights according to the number of events and no events. ${ }^{27}$ We used a continuity correction for studies with no events by adding 0.5 to the events count and 1 to the total sample size.

\section{Patient involvement}

No patients were involved in setting the research question or the outcome measures, nor were they involved in developing plans for design or implementation of the study. No patients were asked to advise on interpretation or writing up of results. There are no plans to disseminate the results of the research to study participants or the relevant patient community.

\section{Results}

\section{Identification of studies}

From 2574 citations, we included 32 studies reporting on 35171 women with twin gestations (29685 dichorionic, 5486 monochorionic pregnancies) (fig 1). ${ }^{1628-55}$ Eighteen studies provided data on both monochorionic

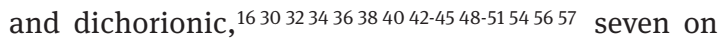
only monochorionic, ${ }^{29} 313739414753$ and seven on only dichorionic twin pregnancies. ${ }^{2833} 3546525558$ Twenty three authors provided relevant unpublished data. ${ }^{16283032-35383941-4347-5456-58}$

\section{Characteristics and quality of included studies}

Fifteen studies on dichorionic pregnancies (17830 women) and 13 on monochorionic pregnancies (2149 women) provided weekly stillbirth data after 34 weeks' gestation. The corresponding neonatal death rates were provided by 13 ( $n=10333)$ studies for dichorionic and 11 ( $n=1461)$ for monochorionic pregnancies. Overall, 14 studies excluded pregnancies complicated by fetal growth restriction, and 28 studies excluded pregnancies with major congenital abnormalities. The diagnoses of fetal growth restriction and congenital abnormalities were made antenatally. Two studies reviewed the postmortem findings of stillborn babies for evidence of growth restriction. There were no major differences between the studies in the definitions of stillbirths, neonatal mortality, and morbidity outcomes (appendix 2). The number of stillbirths and neonatal deaths between 26 and 33+6 weeks and after 34 weeks' gestation in individual studies for monochorionic and dichorionic pregnancies are provided in appendix 3.

The quality of the studies was adequately representative in 27 (27/32, 84\%) and inadequately or unclearly 


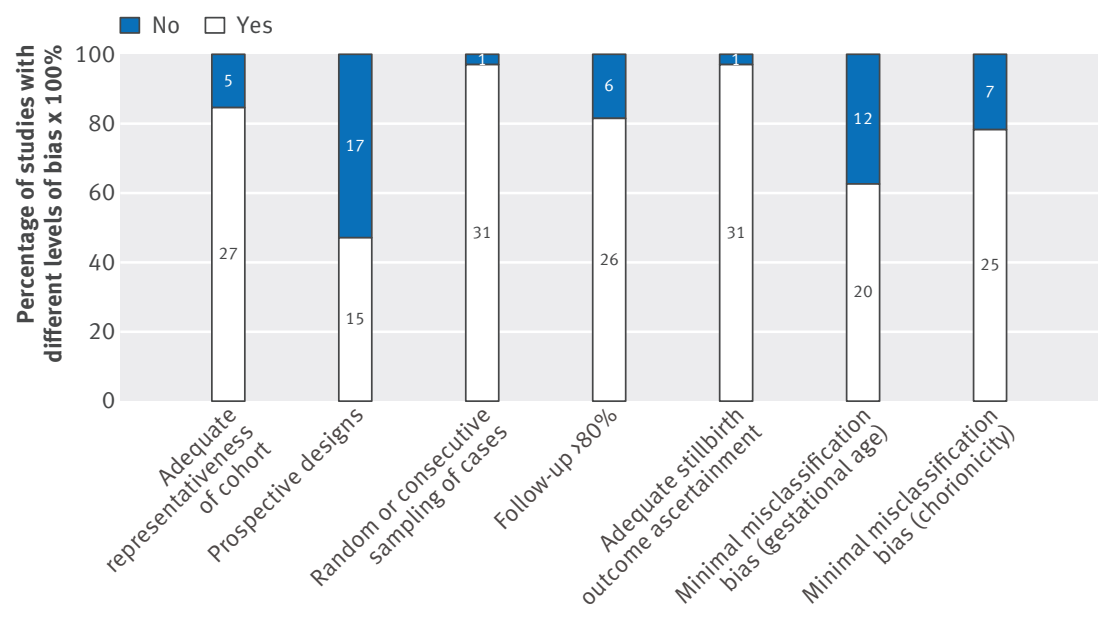

Fig 2 | Risk of bias in studies included in systematic review on prospective risk of stillbirth and neonatal complications in uncomplicated twin pregnancies

representative in five $(5 / 32,16 \%)$ (fig 2). Fifteen of the included studies (15/32) were prospective, and, of these, $12(12 / 32,38 \%)$ were nested cohorts in randomised trials. Most studies used random or consecutive sampling methods (31/32, 97\%), achieved adequate follow-up (26/32, 81\%), and had low ascertainment bias in determining stillbirth outcome (31/32, 97\%). Twenty studies had a low risk of misclassification bias for assessment of gestational age $(20 / 32,63 \%)$ and determination of chorionicity (25/32, 78\%).

\section{Stillbirth and neonatal mortality beyond 34 weeks' gestation}

Dichorionic twin pregnancies

The prospective risk of stillbirth was 1.2 per 1000 pregnancies (95\% confidence interval 0.7 to 1.8 ) at 34+0-6 weeks, with the corresponding risk of neonatal death of 6.7 per 1000 pregnancies (3.3 to 13.5) (table 1). The risk of stillbirth was significantly lower than the risk of neonatal death at 34+0-6 weeks (risk difference $-5.8 / 1000$, -10.4 to $\left.-1.2 / 1000 ; I^{2}=0 \%\right)$ and $35+0-6$ weeks $(-5.1 / 1000$, -8.7 to $\left.-1.6 / 1000 ; I^{2}=0 \%\right)$. The perinatal risks were balanced at $37+0-6$ weeks $(1.2 / 1000,-1.3$ to $3.6 / 1000$; $\left.\mathrm{I}^{2}=0 \%\right)$, beyond which the risks of stillbirth $(10.6,7.1$ to 15.3) significantly outweighed the risk of neonatal death (1.5/1000, 0.7 to 3.3) from delivery (risk difference $8.8 / 1000$, 3.6 to $14 / 1000 ; I^{2}=0 \%$ ) (fig 3). Analysis in which we excluded fetuses with congenital abnormalities showed results similar to the main analysis (appendix 4). Exclusion of studies with low external validity showed a trend towards an increased risk of stillbirth rather than an increased risk of neonatal death beyond 37+0-6 weeks, which was not significant.

\section{Monochorionic twin pregnancies}

At 34 weeks, the prospective risk of stillbirth and neonatal mortality rates in monochorionic pregnancies were 0.9 (95\% confidence interval 0.1 to 3.4 ) and 12.1 (4.2 to 34.3), respectively. The risks of neonatal death were higher than the risks of stillbirth at 34+0-6 (risk difference $-15.6 / 1000,95 \%$ confidence interval -40.4 to 9.1/1000; $\left.\mathrm{I}^{2}=0 \%\right)$ and $35+0-6$ weeks $(-2.4 / 1000,-17.6$ to $12.8 / 1000 ; I^{2}=0 \%$ ), which were not significant (fig 3). Beyond 36+0-6 weeks, we observed a trend where the risk of stillbirth $(9.6 / 1000,3.9$ to 19.7) was higher than the risk of neonatal death $(3.6 / 1000,1.2$ to 11.1$)$ with a risk difference of $2.5 / 1000$ ( -12.4 to $17.4 / 1000 ; I^{2}=0 \%$ ). Sensitivity analysis in which we excluded studies with congenitally malformed fetuses (appendix 4) and studies with low external validity showed similar findings.

All analyses were restricted up to 38 weeks for monochorionic twin pregnancies and up to 39 weeks for dichorionic twin pregnancies because of the lack of availability of robust data beyond this period.

\section{Neonatal morbidity beyond 34 weeks' gestation}

We observed a consistent and significant reduction in the rates of assisted ventilation, respiratory distress

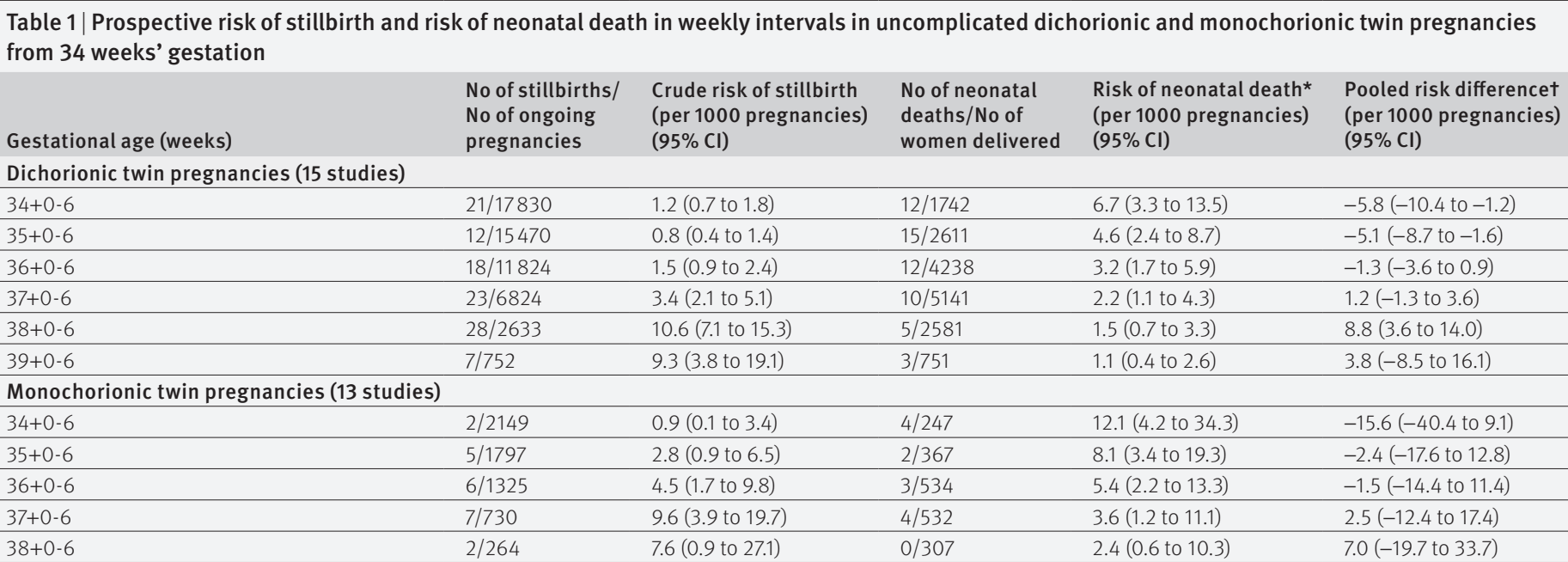

*Risk of neonatal death computed by multilevel logistic regression model (see text).

tIndividual studies risk differences pooled by fixed effect model meta-analysis (see text). 


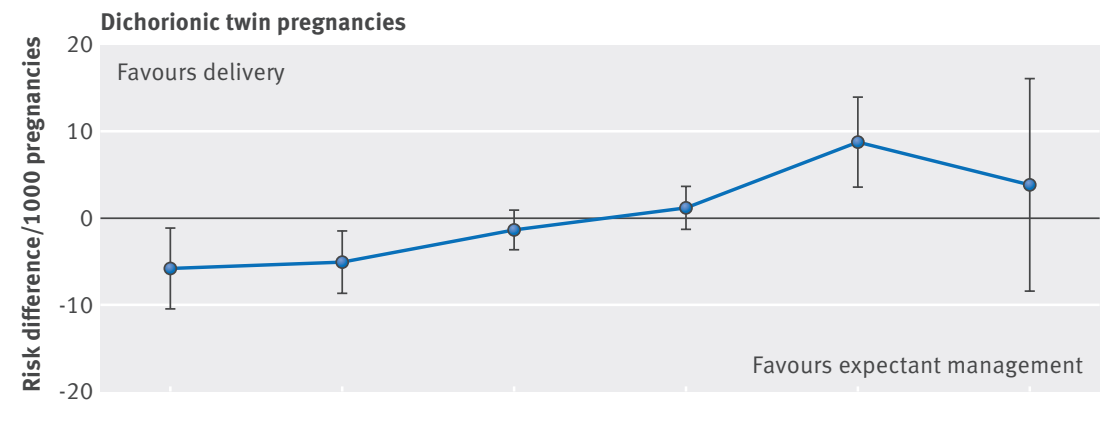

Risk difference/1000 pregnancies $(95 \% \mathrm{Cl})$

\begin{tabular}{|c|c|c|c|c|c|}
\hline $\begin{array}{c}-5.8 \\
(-10.4 \text { to }-1.2)\end{array}$ & $\begin{array}{c}-5.1 \\
(-8.7 \text { to }-1.6)\end{array}$ & $\begin{array}{c}-1.3 \\
(-3.6 \text { to } 0.9)\end{array}$ & $\begin{array}{c}1.2 \\
(-1.3 \text { to } 3.6)\end{array}$ & $\begin{array}{c}8.8 \\
\text { (3.6 to } 14.0)\end{array}$ & $\begin{array}{c}3.8 \\
(-8.5 \text { to } 16.1)\end{array}$ \\
\hline Stillbirth & & & & & \\
\hline 21 & 12 & 18 & 23 & 28 & 7 \\
\hline Ongoing pregnancies & & & & & \\
\hline 17830 & 15470 & 11824 & 6824 & 2633 & 752 \\
\hline Neonatal death & & & & & \\
\hline 12 & 15 & 12 & 10 & 5 & 3 \\
\hline Deliveries & & & & & \\
\hline 1742 & 2611 & 4238 & 5141 & 2581 & 751 \\
\hline
\end{tabular}

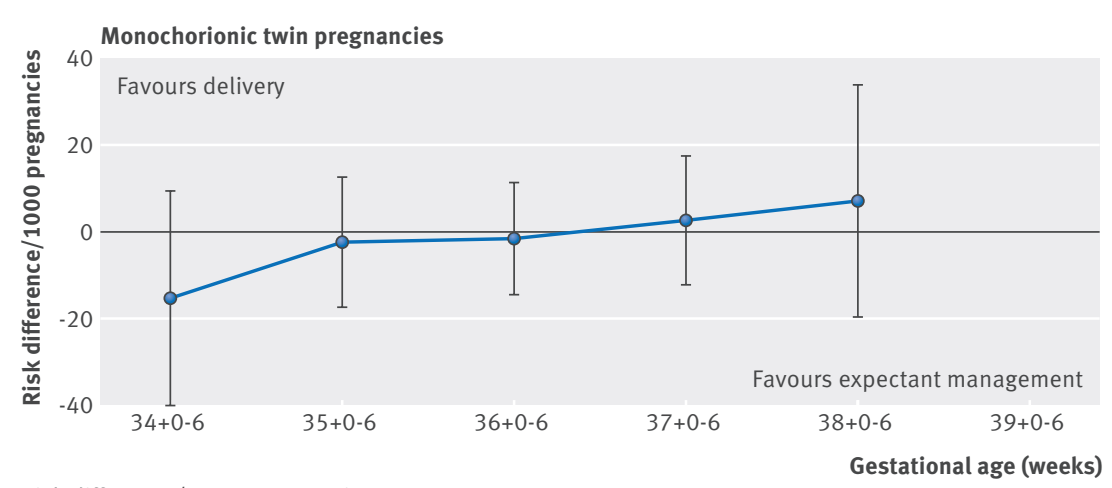

Risk difference/1000 pregnancies $(95 \% \mathrm{Cl})$

$-15.6-2.4$

$-1.5$

2.5

7.0

$(-40.4$ to 9.1$) \quad(-17.6$ to 12.8$) \quad(-14.4$ to 11.4$) \quad(-12.4$ to 17.4$) \quad(-19.7$ to 33.7$)$

Stillbirth

Ongoing pregnancies

49

Neonatal death

\section{9}

Deliveries

247

5
1797
2

6

1325

730

\section{3}

534

4

532

307

Fig 3 | Prospective risks of stillbirths from expectant management compared with risks of neonatal mortality from delivery at weekly intervals from 34 weeks' gestation in twin pregnancies outcomes in two weekly time periods are shown in appendix 6. Neonatal morbidity reduced with increasing gestational age in all twin pregnancies. In both monochorionic and dichorionic pregnancies, the most common neonatal complications were respiratory distress syndrome, septicaemia, admission to neonatal intensive care unit and need for assisted ventilation.

\section{Publication bias and small studies effect}

Funnel plots showed a slight asymmetry for stillbirth outcome in dichorionic pregnancies (Peter's test $\mathrm{P}=0.037$ ), consistent with the finding that smaller studies are published if they show higher rates of stillbirth. We found no more significant asymmetries for outcome of neonatal death.

\section{Discussion}

In dichorionic twin pregnancies the perinatal risks are balanced until 37+0-6 weeks' gestation, and until $36+0-6$ in monochorionic pregnancies, with higher risks of stillbirths than neonatal deaths beyond this gestation. Our study provides comprehensive estimates comparing risks of stillbirth and neonatal mortality at various gestational ages, which is required for the planning of delivery in uncomplicated twin pregnancies.

\section{Strengths and limitations}

This was the largest and most robust systematic review to date on stillbirths and neonatal outcomes in twin pregnancies. In addition to the risk of stillbirth at each gestational week, we provided risk estimates of the other equally important consequence of early deliverynamely, neonatal death. Ours is the first review to provide estimates of neonatal morbidity for specific chorionicity and gestational age in twin pregnancies. All the included studies were relatively recent and published within the past 10 years. The sharing of unpublished aggregate and individual patient data by authors enabled us to provide our findings in clinically relevant weekly intervals. We chose the gestational timeframes to reduce bias from varied lengths of follow-up. We minimised heterogeneity by excluding studies without clear details on twin-to-twin transfusion syndrome. Our sensitivity analyses allowed us to assess the risks in pregnancies not complicated by congenital malformation and by fetal growth restriction.

Our findings were limited by the policy of planned delivery beyond 37 and 38 weeks' gestation in most studies. This reduced the available sample size near term, particularly in monochorionic pregnancies, and could have led to underestimation of risk of stillbirth in the last weeks of pregnancy. Although the observed increased risk of stillbirth was higher than the increased risk of neonatal death beyond 36 weeks in monochorionic pregnancies, the differences were not significant. This was because of the gradual decline in the number of pregnancies available for analysis, which could be attributed to the policy of elective delivery near term. Most studies did not provide details on whether stillbirth was diagnosed antenatally or at birth. Given the policy of regular ultrasound for fetal monitoring in most 


\begin{tabular}{|c|c|c|c|c|c|c|c|c|c|c|}
\hline \multirow{2}{*}{$\begin{array}{l}\text { Gestational } \\
\text { age }\end{array}$} & \multicolumn{2}{|c|}{ Assisted ventilation } & \multicolumn{2}{|c|}{$\begin{array}{l}\text { Hypoxic ischaemic } \\
\text { encephalopathy or } \\
\text { neonatal seizures }\end{array}$} & \multicolumn{2}{|c|}{$\begin{array}{l}\text { Respiratory distress } \\
\text { syndrome (RDS) }\end{array}$} & \multicolumn{2}{|c|}{ Septicaemia } & \multicolumn{2}{|c|}{ NICU admission } \\
\hline & $\mathrm{n} / \mathrm{N}$ & $\operatorname{Risk}^{*}(95 \% \mathrm{Cl})$ & $\mathrm{n} / \mathrm{N}$ & $\operatorname{Risk}^{*}(95 \% \mathrm{Cl})$ & $\mathrm{n} / \mathrm{N}$ & $\operatorname{Risk}^{*}(95 \% \mathrm{Cl})$ & $n / N$ & Risk* $(95 \% \mathrm{Cl})$ & $\mathrm{n} / \mathrm{N}$ & $\operatorname{Risk}^{*}(95 \% \mathrm{Cl})$ \\
\hline \multicolumn{11}{|c|}{ Monochorionic } \\
\hline No of studies & 7 & - & 7 & - & 10 & - & 11 & - & 9 & - \\
\hline $34+0-34+6$ & $23 / 143$ & 112.9 (49.2 to 238.3) & 0/101 & $\mathrm{N} / \mathrm{A}$ & $38 / 178$ & 176.7 (105.2 to 281.5$)$ & 9/196 & 54.3 (23.9 to 118.8$)$ & $61 / 157$ & 501.6 (306.1 to 696.6) \\
\hline $35+0-35+6$ & $17 / 206$ & $61.3(26.9$ to 133.3$)$ & $0 / 144$ & $\mathrm{~N} / \mathrm{A}$ & $22 / 261$ & $74.2(43.6$ to 123.7$)$ & $7 / 283$ & 24.4 (11.7 to 50.5) & $61 / 229$ & $316.8(173.2$ to 506.6$)$ \\
\hline $36+0-36+6$ & $14 / 289$ & 32.4 (13.7 to 74.3$)$ & $1 / 238$ & $\mathrm{~N} / \mathrm{A}$ & $13 / 365$ & 29.1 (15.9 to 52.5) & $3 / 406$ & 10.8 (4.6 to 24.9) & $44 / 319$ & 176.1 (88.0 to 321.4) \\
\hline $37+0-37+6$ & $7 / 308$ & $16.9(6.6$ to 42.5$)$ & $0 / 242$ & $\mathrm{~N} / \mathrm{A}$ & $9 / 424$ & 11.1 (5.3 to 22.8) & $3 / 452$ & $4.7(1.6$ to 14.1$)$ & $34 / 345$ & 89.7 (41.3 to 183.9) \\
\hline $38+0-38+6$ & $2 / 163$ & 8.7 (3.0 to 25.0) & $0 / 137$ & $\mathrm{~N} / \mathrm{A}$ & $0 / 225$ & $4.2(1.7$ to 10.2$)$ & $0 / 237$ & $2.1(0.5$ to 8.5$)$ & $5 / 168$ & 43.4 (18.4 to 99.3) \\
\hline \multicolumn{11}{|l|}{ Dichorionic } \\
\hline No of studies & 9 & - & 2 & - & 13 & - & 11 & - & 11 & - \\
\hline $34+0-34+6$ & $75 / 372$ & 97.3 (36.4 to 235.4) & $1 / 190$ & $3.6(0.7$ to 19.7$)$ & $94 / 490$ & 130.1 (77.8 to 209.6) & $11 / 465$ & 9.5 (2.4 to 36.1$)$ & $181 / 401$ & 492.6 (317.4 to 669.6$)$ \\
\hline $35+0-35+6$ & $72 / 518$ & 56.8 (20.9 to 145.6$)$ & $1 / 304$ & 2.8 (0.9 to 9.2) & $63 / 695$ & 69.3 (40.9 to 114.9) & $6 / 659$ & 6.4 (1.7 to 23.5) & $179 / 577$ & 315.4 (182.3 to 487.8) \\
\hline $36+0-36+6$ & $69 / 779$ & 32.6 (11.8 to 86.9) & $1 / 530$ & 2.2 (0.9 to 5.3) & 49/1013 & 35.7 (20.8 to 60.8) & $10 / 943$ & $4.3(1.2$ to 15.7$)$ & $152 / 853$ & 179.5 (95.9 to 310.9) \\
\hline $37+0-37+6$ & $41 / 1146$ & 18.5 (6.5 to 51.0$)$ & $1 / 820$ & $1.7(0.6$ to 4.8$)$ & $46 / 1563$ & 18.1 (10.2 to 31.8$)$ & $8 / 1447$ & 2.9 (0.8 to 10.9) & $154 / 1296$ & 94.1 (47.7 to 177.2) \\
\hline $38+0-38+6$ & $21 / 834$ & 10.4 (3.6 to 29.7) & $0 / 601$ & 1.3 (0.3 to 5.9) & $17 / 1120$ & 9.1 (4.9 to 16.7) & 7/1081 & $2.0(0.5$ to 7.8$)$ & $77 / 932$ & $47.0(22.9$ to 94.0$)$ \\
\hline $39+0-39+6$ & $2 / 103$ & 5.8 (2.0 to 17.3$)$ & $1 / 63$ & 1.1 (0.1 to 8.2) & $1 / 258$ & $4.5(2.3$ to 8.8$)$ & $1 / 235$ & 1.3 (0.3 to 5.8$)$ & $5 / 134$ & 22.9 (10.8 to 47.9) \\
\hline
\end{tabular}

$\mathrm{NICU}=$ neonatal intensive care unit; $\mathrm{n}=$ No of adverse outcomes; $\mathrm{N}=$ No of women delivered in that 1 week gestational time period

*Risk/1000 deliveries.

units, however, we expect the interval between diagnosis and delivery to be small. The variation observed in the clinical management of twin pregnancies and neonatal care after delivery between centres could also have influenced the outcomes. ${ }^{59}$ The small study effects that we observed for stillbirth outcomes in monochorionic pregnancies could be attributed to selective reporting or publication of data from centres showing good outcomes and small sample sizes. We ensured that all data were available from 34 weeks for women in randomised trials, but it is possible that women with early stillbirth would not be in the analysis.

We undertook a pragmatic approach by including all twin pregnancies not complicated by twin to twin transfusion syndrome. We were not able to provide separate estimates for individual causes of neonatal mortality or for elective and emergency deliveries. The results did not vary after we excluded pregnancies complicated by fetal growth restriction, one of the main indications for emergency delivery. We focused only on short term neonatal morbidity because of paucity of data. ${ }^{6061}$ We provided the risk estimates per pregnancy and not per fetus, as it is likely that mothers would consider the prospective risk of death in either of their fetuses in utero or after delivery to be equally important. This, however, limited our ability to distinguish between those pregnancies with a single or double adverse outcome.

Primary studies, ${ }^{15} 16293962$ systematic reviews, ${ }^{13}$ and guideline bodies ${ }^{963}$ have been limited in their interpretation of evidence on the timing of delivery in twin pregnancies because of paucity of data and inadequate methods. Firstly, they compared the risks of stillbirth in twin pregnancies at various gestational weeks with those at, or near, term, without considering the inherent longitudinal design with women repeatedly observed during the pregnancy. ${ }^{64}$ Secondly, some studies estimated risk using survival analysis (Kaplan-Meier method). Delivery was not considered as a competing event for the outcome of stillbirth and might have overestimated the risk. ${ }^{65}$ Thirdly, studies did not provide gestational age specific pooled estimates for significant neonatal morbidity. ${ }^{1366}$ Fourthly, existing recommendations on the timing of delivery are based on gestational age specific risk of stillbirth and do not formally take into account the benefit gained by reducing neonatal deaths. ${ }^{1367}$ Finally, the risks of fetal death in twins were not assessed beyond 36 weeks' gestation, and the rationale behind the choice of the gestational ages for elective delivery is not clear. ${ }^{9}$ Other large epidemiological studies on perinatal outcomes in twins were limited by the lack of detail regarding the chorionicity and the definition of uncomplicated monochorionic pregnancies. 6869

\section{Implications of findings}

Some current recommendations offer expectant management of uncomplicated dichorionic twin pregnancies until 38+0-6. ${ }^{810}$ Based on our findings, this poses a risk of an additional 8.8 perinatal deaths compared with delivery a week earlier. Although we observed a change in the direction of the difference in risk, with more stillbirths than neonatal deaths beyond 36 weeks in monochorionic twin pregnancies, the difference was not significant. The variation in policies for management of monochorionic twin pregnancies, with some advocating delivery as early as $34+0-6$ weeks, ${ }^{810}$ have contributed to the fall in number of pregnancies available for analysis in later gestation. Based on our findings, there is no clear evidence to recommend early preterm delivery routinely before 36 weeks in monochorionic pregnancies. The information on risks provided in twin pregnancies will complement the ongoing national and international efforts to reduce the rates of stillbirths ${ }^{70}$ and unexpected neonatal complications in babies born near term.

With a 10th of all twin pregnancies delivering before 32 weeks, our estimates on early preterm neonatal 
mortality and morbidity provide crucial information to counsel mothers at risk of early preterm delivery. ${ }^{71-73}$ Our work has fulfilled the unmet needs in this specialty, in which current estimates on the predicted probability of survival of newborns, especially early preterm twins, are based on extrapolated data from small samples and do not take into account the effects of chorionicity. ${ }^{14}$ Although we did not incorporate economic evaluation in our review, avoidance of early delivery has the potential for huge savings to the healthcare system, with one study suggesting savings up to $\$ 70000$ (£53600, €63000) per infant. ${ }^{62}$

The feasibility of a definitive randomised trial on optimal timing of delivery in twin pregnancies is limited, given the huge numbers needed to assess outcomes. ${ }^{1516}$ Individual patient data meta-analysis would allow us to assess the effect of factors such as monitoring of the fetuses, level of newborn care, and mode of delivery on outcomes. There is a need to study the effects of delivery before 37 weeks and the loss of a co-twin in monochorionic pregnancies on long term infant neurodevelopment. ${ }^{617475}$

\section{Conclusion}

For women with dichorionic pregnancies, delivery should be considered at 37 weeks' gestation to minimise the risk of perinatal deaths near term. There is insufficient evidence to recommend routine delivery before 36 weeks' gestation in monochorionic twins. Our estimates of fetal and neonatal outcomes at various gestational ages in twin pregnancies should be taken into account when decisions are made on timing of delivery.

\section{AUTHOR AFFILIATIONS}

'Women's Health Research Unit, Barts and the London School of Medicine and Dentistry, Queen Mary University of London E1 2AB, UK 2Julius Centre for Health Sciences and Primary Care, University Medical Centre Utrecht, Utrecht, Netherlands

${ }^{3}$ Department of Obstetrics and Gynaecology, Academic Medical Centre, Amsterdam, Netherlands

${ }^{4}$ Stanford Prevention Research Center, Stanford University, Palo Alto, Stanford, CA 94305, USA

${ }^{5}$ Clinical Biostatistics Unit, Instituto Ramón y Cajal de Investigación Sanitaria (IRYCIS), Madrid, Spain

${ }^{6}$ Fetal Medicine Unit, St George's Healthcare NHS Trust, London SW17 OQT, UK

${ }^{7}$ Evaluative Clinical Sciences, Women and Babies Research Program, Sunnybrook Research Institute, Toronto, ON M4N 3M5, Canada

${ }^{8}$ Department of Obstetrics and Gynecology, University of British Columbia, Vancouver, BC V6Z 2K5, Canada

${ }^{9}$ Department of Newborn and Developmental Paediatrics, Women and Babies Research Program, Sunnybrook Health Sciences Centre, Toronto, ON M4N 3M5, Canada

${ }^{10}$ Department of Gynaecology and Obstetrics, Diakonessenhuis, 3582 KE Utrecht, Netherlands

${ }^{11}$ Department of Obstetrics-Gynaecology, University Hospitals, 3000 Leuven, Belgium

${ }^{12}$ Department of Development and Regeneration: Pregnancy, Fetus and Neonate, KU Leuven, Belgium

${ }^{13}$ Department of Obstetrics and Gynaecology, Academic Medical Centre, 1105 AZ Amsterdam, Netherlands

${ }^{14}$ University of Edinburgh MRC Centre for Reproductive Health, Queen's Medical Research Institute, Edinburgh EH16 4TY, UK

${ }^{15}$ Department of Obstetrics and Gynecology, University of

Mississippi Medical Center, Jackson, MS, USA
${ }^{16}$ Obstetrix Collaborative Research Network, Center for Research, Education and Quality, Mednax National Medical Group, FL 33323, USA

17University of California Irvine, Irvine, CA 92697, USA

${ }^{18}$ Maternal-Fetal Medicine Unit, Instituto Valenciano de Infertilidad, University of Valencia, Spain

${ }^{19}$ Department of Obstetrics and Gynaecology, Faculty of Medicine, University of Valencia, Jefe Servicio Obstetricia Hospital U P La FE, Torre F, Valencia, Espana

${ }^{20}$ Department of Obstetrics, University Hospital La Fe, Valencia, 46026 València, Spain

${ }^{21}$ Centre of Fetal Medicine, Department of Obstetrics, Copenhagen University Hospital, Rigshospitalet, Copenhagen, Denmark

${ }^{22}$ Department of Obstetrics and Gynaecology, Medical University of Vienna, 1090 Wien, Austria

${ }^{23}$ Department of Obstetrics and Gynaecology, American University of Beirut Medical Centre, Riad El Solh, Beirut 1107 2020, Lebanon

${ }^{24}$ The Egyptian IVF Centre, Maadi and Department of Obstetrics and Gynaecology, Faculty of Medicine, Cairo University, Oula, Giza, Egypt ${ }^{25}$ Department of Obstetrics and Gynecology, Women and Infants Hospital, Brown University Women and Infants Hospital, Providence, RI 02905, USA

${ }^{26}$ Royal College of Surgeons in Ireland, Rotunda Hospital, Dublin, Republic of Ireland

27Department of Maternal Fetal Medicine, Osaka Medical Center and Research Institute for Maternal and Child Health, Izumi, Osaka 594-1101, Japan

${ }^{28}$ Department of Obstetrics and Gynecology, University of Milano-Bicocca, 20126 Milan, Italy

${ }^{29}$ Division of Maternal Fetal Medicine, Department of Obstetrics and Gynecology, Brigham and Women's Hospital, Harvard Medical School, Boston, MA 02115, USA

${ }^{30}$ Robinson Research Institute, and Discipline of Obstetrics and Gynaecology, University of Adelaide, North Adelaide SA 5006, Australia

${ }^{31}$ Department of Obstetrics and Gynecology, Medical University of South Carolina, Charleston, SC 29403, USA

32University of Aberdeen, Dugald Baird Centre for Research on Women's Health, Aberdeen Maternity Hospital, Aberdeen AB25 2ZL, UK

${ }^{33}$ Department of Obstetrics and Gynecology, Alberta Health Services, Calgary, AB T2N 2T9, Canada

${ }^{34}$ Australian Research Centre for Health of Women and Babies, Robinson Institute, University of Adelaide, North Adelaide, SA 5006 Australia

${ }^{35}$ Clinical Biostatistics Unit, Hospital Ramón y Cajal (IRYCIS), Madrid, Spain

${ }^{36}$ CIBER Epidemiology and Public Health (CIBERESP), Madrid, Spain

We thank Stephen Wood who contributed to the acquisition of data for the work, revisions of the draft, and analysis (as a peer reviewer).

Contributors: BT and STh are joint lead authors. Substantial contribution to conception and design, acquisition, analysis, and interpretation of data for work (BT); substantial contribution to conception and design, acquisition, analysis, and interpretation of data for work and developed the review protocol (STh); substantial contribution to acquisition, analysis, interpretation of data for work (FC-S, ES, JB, KSJ, EA); substantial contribution to analysis and interpretation of data for work (DA-M, JZ); substantial contribution to acquisition of data for work (AK, KH, LL, AL, SL, JEN, JM, CAC, TJG, KM, VS, AP, LR, KW, AN, MA, DR, ET, FB, FMR, JNR, JMD, RBN, SB, STa BWJM); performing all statistical analyses (DA-M, JZ); writing of initial drafts and revisions (FC-S); contribution to initial and critical revisions of drafts (JZ); and writing of critical revision of drafts (ES, DA-M, AK, JB, KSJ, EA, KH, LL, AL, SL, JEN, JM, CAC, TJG, KM, VS, AP, LR, KW, AN, MA, DR, ET, FB, FMR, JNR, JMD, RBN, SB, STa, BWJM, BT, STh). All authors approved the final version and agree to be accountable for all aspects of work.

Funding: This research received no specific grant from any funding agency in the public, commercial, or not-for-profit sectors.

Competing interests: All authors have completed the ICMJE uniform disclosure form at www.icmje.org/coi_disclosure.pdf and declare: no support from any organisation for the submitted work; no financial relationships with any organisations that might have an interest in the submitted work in the previous three years; no other relationships or activities that could appear to have influenced the submitted work.

Ethical approval: Not required. 
Data sharing: No additional data available.

Transparency: The lead author (the manuscript's guarantor) affirms that the manuscript is an honest, accurate, and transparent account of the study being reported; that no important aspects of the study have been omitted; and that any discrepancies from the study as planned (and, if relevant, registered) have been explained.

This is an Open Access article distributed in accordance with the Creative Commons Attribution Non Commercial (CC BY-NC 3.0) license, which permits others to distribute, remix, adapt, build upon this work non-commercially, and license their derivative works on different terms, provided the original work is properly cited and the use is noncommercial. See: http://creativecommons.org/licenses/by-nc/3.0/.

1 Peter C, Wenzlaff P, Kruempelmann J, Alzen G, Bueltmann E. Perinatal morbidity and early neonatal mortality in twin pregnancies. Open J Obstet Gynecol 2013;3:78-89doi:10.4236/ ojog.2013.31017.

2 Ortibus E, Lopriore E, Deprest J, et al. The pregnancy and long-term neurodevelopmental outcome of monochorionic diamniotic twin gestations: a multicenter prospective cohort study from the first trimester onward. Am J Obstet Gynecol 2009;200:494.e1-8. doi:10.1016/j.ajog.2009.01.048.

3 Russo FM, Pozzi E, Pelizzoni F, et al. Stillbirths in singletons, dichorionic and monochorionic twins: a comparison of risks and causes. EurJ Obstet Gynecol Reprod Biol 2013;170:131-6. doi:10.1016/j.ejogrb.2013.06.014

4 Poulter D. Multiple Births. Parliamentary business 2014; Information on the number of obstetrics claims received between 1 April 2004 and 2031 March 2014 which have involved a multiple pregnancy are set out in the following tables. http://www.parliament.uk/business/ publications/written-questions-answers-statements/writtenquestion/Commons/2014-12-05/217336/, 2016.

5 Royal Australain and New Zealand Colleges of Obstetricians and Gynaecologists. Management of monochorionic twin pregnancy. C-Obs 42.RANZCOG, 2014: 1-11.

6 Flenady V, Wojcieszek AM, Middleton P, et al. Lancet Ending Preventable Stillbirths study group Lancet Stillbirths In High-Income Countries Investigator Group. Stillbirths: recall to action in high-income countries. Lancet 2016;387:691-702. doi:10.1016/ S0140-6736(15)01020-X

7 Heazell AE, Whitworth MK, Whitcombe J, et al. Research priorities for stillbirth: process overview and results from UK Stillbirth Priority Setting Partnership. Ultrasound Obstet Gynecol 2015;46:641-7. doi:10.1002/uog.15738.

8 American College of Obstetricians and Gynecologists Society for Maternal-Fetal Medicine. ACOG Practice Bulletin No. 144: Multifetal gestations: twin, triplet, and higher-order multifetal pregnancies. Obstet Gynecol 2014:123:1118-32 doi:10.1097/01.AOG.0000446856.51061.3e.

9 NICE. Multiple pregnancy. The management of twin and triplet pregnancies in the antenatal period. NICE clinical guideline 129. National Institute for Health and Clinical Excellence, 2011.

10 Spong CY, Mercer BM, D’alton M, Kilpatrick S, Blackwell S, Saade G. Timing of indicated late-preterm and early-term birth. Obstet Gynecol 2011;118:323-33. doi:10.1097/AOG.0b013e3182255999.

11 Cleary-Goldman J, D’Alton ME. Prospective risk of intrauterine death of monochorionic-diamniotic twins. Am J Obstet Gynecol 2007;196:e112, author reply e11-2. doi:10.1016/j.ajog.2006.09.047.

12 Vayssière C, Benoist G, Blondel B, et al. French College of Gynaecologists and Obstetricians. Twin pregnancies: guidelines for clinical practice from the French College of Gynaecologists and Obstetricians (CNGOF). Eur J Obstet Gynecol Reprod Biol 2011;156:127. doi:10.1016/j.ejogrb.2010.12.045.

13 Danon D, Sekar R, Hack KE, Fisk NM. Increased stillbirth in uncomplicated monochorionic twin pregnancies: a systematic review and meta-analysis. Obstet Gynecol 2013;121:1318-26. doi:10.1097/ AOG.0b013e318292766b.

14 Draper ES, Manktelow B, Field DJ, James D. Prediction of survival for preterm births by weight and gestational age: retrospective population based study. BM/1999:319:1093-7. doi:10.1136/bmj.319.72171093.

15 Suzuki S, Otsubo Y, Sawa R, Yoneyama Y, Araki T. Clinical trial of induction of labor versus expectant management in twin pregnancy. Gynecol Obstet Invest 2000:49:24-7. doi:10.1159/000010207.

16 Dodd JM, Crowther CA, Haslam RR, Robinson JS. Twins Timing of Birth Trial Group. Elective birth at 37 weeks of gestation versus standard care for women with an uncomplicated twin pregnancy at term: the Twins Timing of Birth Randomised Trial. BJOG 2012;119:964-73. doi:10.1111/j.1471-0528.2012.03356.x.

17 Cheong-See F, Schuit E, Arroyo-Manzano D, et al. Optimal timing of delivery in women with twin pregnancies: A meta-analysis of evidence. PROSPERO: International prospective register of systematic reviews. CRD42014007538

18 Liberati A, Altman DG, TetzlaffJ, et al. The PRISMA statement for reporting systematic reviews and meta-analyses of studies that evaluate health care interventions: explanation and elaboration. PLoS Med 2009;6:e1000100. doi:10.1371/journal.pmed.1000100.
19 Mol BW, Ruifrok AE. Global Obstetrics Network. Global alignment, coordination and collaboration in perinatal research: the Global Obstetrics Network (GONet) Initiative. Am J Perinatol 2013;30:163-6.

20 Connect EBM. http://blizard.qmul.ac.uk/research-generation/538ebm-connect.html, 2014

21 Schuit E, Stock S, Groenwold RH, et al. Progestogens to prevent preterm birth in twin pregnancies: an individual participant data meta-analysis of randomized trials. BMC Pregnancy Childbirth 2012;12:13. doi:10.1186/1471-2393-12-13.

22 Glasziou P, Irwig L, Bain C, Colditz G. Systematic reviews in health care. A practical guide.2nd ed. Cambridge University Press, 2004 : 67-73.

23 Latthe P, Latthe M, Say L, Gülmezoglu M, Khan KS. WHO systematic review of prevalence of chronic pelvic pain: a neglected reproductive health morbidity. BMC Public Health 2006;6:177. doi:10.1186/1471-2458-6-177.

24 Khan KS, Wojdyla D, Say L, Gülmezoglu AM, Van Look PFA. WHO analysis of causes of maternal death: a systematic review. Lancet 2006;367:1066-74. doi:10.1016/S0140-6736(06)68397-9.

25 Kramer MS, Liu S, Luo Z, Yuan H, Platt RW, Joseph KS. Fetal and Infant Health Study Group of the Canadian Perinatal Surveillance System. Analysis of perinatal mortality and its components: time for a change?Am J Epidemiol 2002;156:493-7. doi:10.1093/aje/kwf077.

26 Hunter JP, Saratzis A, Sutton AJ, Boucher RH, Sayers RD, Bown MJ. In meta-analyses of proportion studies, funnel plots were found to be an inaccurate method of assessing publication bias. J Clin Epidemiol 2014:67:897-903. doi:10.1016/i.jclinepi.2014.03.003.

27 Moreno SG, Sutton AJ, Ades AE, et al. Assessment of regressionbased methods to adjust for publication bias through a comprehensive simulation study. BMC Med Res Methodol 2009;9:2. doi:10.1186/1471-2288-9-2.

28 Aboulghar MM, Aboulghar MA, Amin YM, Al-Inany HG, Mansour RT, Serour Gl. The use of vaginal natural progesterone for prevention of preterm birth in IVF/ICSI pregnancies. Reprod Biomed Online 2012;25:133-8. doi:10.1016/j.rbmo.2012.03.013.

29 Barigye O, Pasquini L, Galea P, Chambers H, Chappell L, Fisk NM. High risk of unexpected late fetal death in monochorionic twins despite intensive ultrasound surveillance: a cohort study. PLoS Med 2005;2:e172. doi:10.1371/journal.pmed.0020172.

30 Barrett JF, Hannah ME, Hutton EK, et al. Twin Birth Study Collaborative Group. A randomized trial of planned cesarean or vaginal delivery for twin pregnancy. N Engl J Med 2013;369:1295-305. doi:10.1056/ NEJMoa1214939.

31 Berezowsky A, Yinon Y, Mazaki-Tovi S, et al. Neonatal outcome at late prematurity of uncomplicated monochorionic twins: what is the optimal time for delivery?Am J Obstet Gynecol 2014;210:S101 doi:10.1 016/j.ajog.2013.10.213.

32 Breathnach FMMF, McAuliffe FM, Geary M, et al. Perinatal Ireland Research Consortium. Optimum timing for planned delivery of uncomplicated monochorionic and dichorionic twin pregnancies. Obstet Gynecol 2012;119:50-9. doi:10.1097/ AOG.0b013e31823d7b06.

33 Briery CM, Veillon EW, Klauser CK, et al. Progesterone does not prevent preterm births in women with twins. South Med 2009·102:900-4 doi:10.1097/SMI.0b013e3181afee12.

34 Burgess JL, Unal ER, Nietert PJ, Newman RB. Risk of late-preterm stillbirth and neonatal morbidity for monochorionic and dichorionic twins. Am J Obstet Gynecol 2014;210:578.e1-9. doi:10.1016/j. ajog.2014.03.003.

35 Combs CA, Garite T, Maurel K, Das A, Porto M. Obstetrix Collaborative Research Network. 17-hydroxyprogesterone caproate for twin pregnancy: a double-blind, randomized clinical trial. Am J Obstet Gynecol 2011;204:221.e1-8. doi:10.1016/j.ajog.2010.12.042.

36 Domingues AP, Fonseca E, Vasco E, Moura P. Should apparently uncomplicated monochorionic twins be delivered electively at 32 weeks?) Matern Fetal Neonatal Med 2009;22:1077-80. doi:10.3109/14767050903042579.

37 Farah N, Hogan J, Johnson S, Stuart B, Daly S. Prospective risk of fetal death in uncomplicated monochorionic twins. Acta Obstet Gynecol Scand 2012;91:382-5. doi:10.1111/j.1600-0412.2011 01288.x.

38 Hack KE, Derks JB, Elias SG, et al. Increased perinatal mortality and morbidity in monochorionic versus dichorionic twin pregnancies: clinical implications of a large Dutch cohort study. BJOG 2008;115:5867. doi:10.1111/j.1471-0528.2007.01556.x.

39 Hack KE, Derks JB, Elias SG, et al. Perinatal mortality and mode of delivery in monochorionic diamniotic twin pregnancies $\geq 32$ weeks of gestation: a multicentre retrospective cohort study. BJOG 2011;118:1090-7. doi:10.1111/j.1471-0528.2011.02955.x

40 Lee YM, Wylie BJ, Simpson LL, D’Alton ME. Twin chorionicity and the risk of stillbirth. Obstet Gynecol 2008;111:301-8. doi:10.1097/ AOG.0b013e318160d65d.

41 Lewi L, Jani J, Blickstein I, et al. The outcome of monochorionic diamniotic twin gestations in the era of invasive fetal therapy: a prospective cohort study. Am J Obstet Gynecol 2008;199:514.e1-8. doi:10.1016/j.ajog.2008.03.050. 
42 Liem S, Schuit E, Hegeman M, et al. Cervical pessaries for prevention of preterm birth in women with a multiple pregnancy (ProTWIN): a multicentre, open-label randomised controlled trial. Lancet 2013;382:1341-9. doi:10.1016/S0140-6736(13)61408-7.

43 Lim AC, Schuit E, Bloemenkamp K, et al. 17 $\alpha$-hydroxyprogesterone caproate for the prevention of adverse neonatal outcome in multiple pregnancies: a randomized controlled trial. Obstet Gynecol 2011;118:513-20. doi:10.1097/AOG.0b013e31822ad6aa.

44 Mahony R, Mulcahy C, McAuliffe F, Herlihy CO, Carroll S, Foley ME. Fetal death in twins. Acta Obstet Gynecol Scand 2011:90:1274-80. doi:10.1111/j.1600-0412.2011.01239.x.

45 McPherson JA, Odibo AO, Shanks AL, Roehl KA, Macones GA, Cahill AG. Impact of chorionicity on risk and timing of intrauterine fetal demise in twin pregnancies. Am J Obstet Gynecol 2012;207:190.e1-6. doi:10.1016/j.ajog.2012.07.031

46 Morikawa M, Yamada T, Yamada T, Sato S, Cho K, Minakami H. Prospective risk of stillbirth: monochorionic diamniotic twins vs. dichorionic twins. J Perinat Med 2012;40:245-9. doi:10.1515/ jpm-2011-0205.

47 Nakayama S, Ishii K, Kawaguchi H, et al. Perinatal outcome of monochorionic diamniotic twin pregnancies managed from early gestation at a single center. J Obstet Gynaecol Res 2012;38:692-7. doi:10.1111/j.1447-0756.2011.01759.x

48 Norman JE, Mackenzie F, Owen P, et al. Progesterone for the prevention of preterm birth in twin pregnancy (STOPPIT): a randomised, double-blind, placebo-controlled study and meta-analysis. Lancet 2009;373:2034-40. doi:10.1016/S0140-6736(09)60947-8.

49 Rode L, Klein K, Nicolaides KH, Krampl-Bettelheim E, Tabor A. PREDICT Group. Prevention of preterm delivery in twin gestations (PREDICT): a multicenter, randomized, placebo-controlled trial on the effect of vaginal micronized progesterone. Ultrasound Obstet Gynecol 2011;38:272-80. doi:10.1002/uog.9093.

50 Rouse DJ, Caritis SN, Peaceman AM, et al. National Institute of Child Health and Human Development Maternal-Fetal Medicine Units Network. A trial of 17 alpha-hydroxyprogesterone caproate to prevent prematurity in twins. N Engl / Med 2007;357:454-61. doi:10.1056/ NEJMoa070641.

51 Russo FM, Pozzi E, Pelizzoni F, et al. Stillbirths in singletons, dichorionic and monochorionic twins: a comparison of risks and causes. Eur J Obstet Gynecol Reprod Biol 2013;170:131-6. doi:10.1016/j.ejogrb.2013.06.014

52 Serra V, Perales A, Meseguer J, et al. Increased doses of vaginal progesterone for the prevention of preterm birth in twin pregnancies: a randomised controlled double-blind multicentre trial. BJOG 2013;120:50-7. doi:10.1111/j.1471-0528.2012.03448.x

53 Smith NA, Wilkins-Haug L, Santolaya-Forgas J, et al. Contemporary management of monochorionic diamniotic twins: outcomes and delivery recommendations revisited. Am J Obstet Gynecol 2010;203:133.e1-6. doi:10.1016/j.ajog.2010.02.066

54 Southwest Thames Obstetric Research Collaborative (STORK). Prospective risk of late stillbirth in monochorionic twins: a regional cohort study. Ultrasound Obstet Gynecol 2012;39:500-4. doi:10.1002/uog.11110.

55 Suzuki S, Inde Y, Miyake H. Comparison of short-term outcomes of late pre-term singletons and dichorionic twins and optimal timing of delivery. J Obstet Gynaecol 2010;30:574-7. doi:10.3109/01443615.2010.494207.

56 Awwad J, Usta I, Ghazeeri G, et al. A randomised controlled double-blind clinical trial of 17-hydroxyprogesterone caproate for the prevention of preterm birth in twin gestation (PROGESTWIN): evidence for reduced neonatal morbidity. BJOG 2015;122:71-9. doi:10.1111/1471-0528.13031.

57 Bhattacharya S, Black S. Unpublished data from Aberdeen Maternity and Neonatal Databank, 2015.

58 Wood S, Tang S, Ross S, Sauve R. Stillbirth in twins, exploring the optimal gestational age for delivery: a retrospective cohort study. BJOG 2014;121:1284-90, discussion 1291 . doi:10.1111/1471-0528.12866

59 Braunholtz DA, Edwards SJ, Lilford RJ. Are randomized clinical trials good for us (in the short term)? Evidence for a "trial effect". J Clin Epidemiol 2001;54:217-24. doi:10.1016/S0895-4356(00)00305-X.

60 Lorenz JM. Neurodevelopmental outcomes of twins. Semin Perinatol 2012;36:201-12. doi:10.1053/j.semperi.2012.02.005.
61 Woythaler MA, McCormick MC, Smith VC. Late preterm infants have worse 24-month neurodevelopmental outcomes than term infants. Pediatrics 2011:127:e622-9. doi:10.1542/peds.2009-3598.

62 Sullivan AE, Hopkins PN, Weng HY, et al. Delivery of monochorionic twins in the absence of complications: analysis of neonatal outcomes and costs. Am J Obstet Gynecol 2012;206:257.e1-7. doi:10.1016/j. ajog.2011.12.016

63 American College of Obstetricians and Gynecologists Society for Maternal-Fetal Medicine. ACOG Practice Bulletin No. 144: Multifetal gestations: twin, triplet, and higher-order multifetal pregnancies. Obstet Gynecol 2014;123:1118-32. doi:10.1097/01 AOG.0000446856.51061.3e.

64 Tang M-L, Tang NS. Exact Tests for Comparing Two Paired Proportions with Incomplete Data. Biom / 2004;46:72-82doi:10.1002/bimj.200210003.

65 Fong F, Thangaratinam S, Zamora J. Increased stillbirth in uncomplicated monochorionic twin pregnancies: a systematic review and meta-analysis. Obstet Gynecol 2013;122:1302. doi:10.1097| AOG.0000000000000026.

66 Helmerhorst FM, Perquin DA, Donker D, Keirse MJ. Perinatal outcome of singletons and twins after assisted conception: a systematic review of controlled studies. BMJ 2004;328:261. doi:10.1136/bmj.37957.560278.EE.

67 Lee YM. Delivery of twins. Semin Perinatol 2012;36:195-200. doi:10.1053/i.semperi.2012.02.004

68 Kahn B, Lumey LH, Zybert PA, et al. Prospective risk of fetal death in singleton, twin, and triplet gestations: implications for practice. Obstet Gynecol 2003;102:685-92.

69 Cheung YB, Yip P, Karlberg J. Mortality of twins and singletons by gestational age: a varying-coefficient approach. Am J Epidemiol 2000;152:1107-16. doi:10.1093/aje/152.12.1107.

70 RCOG RCoOaG. Each Baby Counts. 2016. https://www.rcog.org.uk/ eachbabycounts.

71 Laws PJHL. Australia's mothers and babies 2006.AlHW National Perinatal Statistics Unit, 2008

72 Elliott JP. High-order multiple gestations. Semin Perinatol 2005;29:305-11. doi:10.1053/j.semperi.2005.08.001.

73 Chan ASJ, Nguyen A, Sage L. Pregnancy Outcome in South Australia 2007.Pregnancy Outcome Unit, 2008.

74 Bérard A, Le Tiec M, De Vera MA. Study of the costs and morbidities of late-preterm birth. Arch Dis Child Fetal Neonatal Ed 2012;97:F329-34. doi:10.1136/fetalneonatal-2011-300969.

75 Hillman SC, Morris RK, Kilby MD. Co-twin prognosis after single fetal death: a systematic review and meta-analysis. Obstet Gynecol 2011:118:928-40. doi:10.1097/AOG.0b013e31822f129d.

Appendix 1: Search strategy in Medline Appendix 2: Characteristics of included studies Appendix 3: Individual study data for stillbirths and neonatal deaths at various gestational ages in monochorionic and dichorionic twin pregnancies Appendix 4: Risks of stillbirths from expectant management compared with neonatal mortality risks from delivery at weekly intervals from 34 weeks' gestation in studies on twin pregnancies without major congenital abnormalities

Appendix 5: Risks of stillbirths and neonatal deaths in dichorionic and monochorionic twin pregnancies between $26+0$ weeks and $33+6$ weeks Appendix 6: Rates of neonatal complications for monochorionic and dichorionic twin pregnancies delivered at various gestational ages between $26+0$ weeks and $33+6$ weeks 